\title{
O olhar sobre o outro em Dancing Girls and Other Stories (1982) de Margaret Atwood
}

\section{A view on the other in Dancing Girls and Other Stories (1982) by Margaret Atwood}

\section{Mabiana CAMARGO* UNICENTRO \\ Neide Garcia PINHEIRO** UNICENTRO}

Resumo: Este artigo analisa dois contos da obra Dancings Girls and Other Stories (1982) da escritora canadense Margaret Atwood. Busca-se identificar e interpretar elementos que sugerem a questão relacionada ao outro, ao estrangeiro, observando sua representação nos contextos multiétnicos em que se desenvolvem os eventos dos contos. Portanto, a análise apoia-se, especialmente, nas teorias pós-modernas de Stuart Hall e Homi Bhabha que afirmam que, devido a uma gama de transformações tecnológicas e sociais consequentes da globalização que transforma o indivíduo e a sociedade rápida e velozmente, há um deslocamento da identidade, antes tida na modernidade como única, completa e singular. Com isso, contraditoriamente, o aumento da crença sobre uma condição étnica primeira reforçam as práticas de preconceito, racismo, xenofobia e em condições religiosas, prolifera-se o fundamentalismo. A partir desse aporte teórico, observar-se-á como os personagens de Atwood expressam-se em relação à identidade, reiterando os paradoxos que envolvem a diversidade cultural e o hibridismo das sociedades multiculturais.

Palavras-chave: Identidade. Literatura canadense. Pós-modernismo.

Abstract: This paper discusses two of the short stories of Dancings Girls and Other Stories (1982) by the Canadian author Margaret Atwood. It aims to identify and interpret elements that suggest the issue of the other, the stranger, as they are represented in the multiethnic contexts of the short stories settings. Therefore, the analysis relies especially on postmodern theories of Stuart Hall and Homi Bhabha. They assert that there is a shift of identity, which was once taken as unique, complete and singular. This shift is due to a range of technological and social transformations resulting from globalization that transforms the individual and the society fast and quickly. As a result, paradoxically, the belief in a primeval ethnic condition reinforces prejudice, racism, xenophobia, and, in religious context, the fundamentalism. From this theoretical framework, this paper will analyze how the characters in Atwood's short stories portray their identity, reiterating the paradoxes that involve the cultural diversity and hybridity of multicultural societies.

Keywords: Identity. Canadian literature. Postmodernism.
* Aluna do Programa de Pós-Graduação Mestrado em Letras da Universidade Estadual do Centro-Oeste. E-mail: c.mabiana@ gmail.com

** Professora doutora adjunta do Departamento de Letras (DELET) da UNICENTRO e professora colaboradora do Programa de PósGraduação Mestrado em Letras da mesma universidade. E-mail: neidinha_2005@ hotmail.com 


\section{Introdução}

As obras de Margaret Atwood são geralmente marcadas pela ênfase à subjetividade feminina. Em grande parte de sua ouvre, as protagonistas são mulheres e suas histórias revelam, explicita ou implicitamente, diversos temas que envolvem o 'drama' de como é ser mulher especialmente na contemporaneidade. A coletânea de quatorze contos Dancing Girls and Other Stories (1982), escolhida para compor o corpus deste trabalho, reflete a conflituosa relação entre mulher e homem, destacando-se a rotina e incerteza dos relacionamentos amorosos e a descrição do agir/sentir da mulher diante de acontecimentos cotidianos de sua vida.

Nessa obra, Atwood também oferece indagações sobre outros temas tais como, a reflexão sobre a morte e a complexidade da comunicação e entendimento que permeiam os diversos tipos de relações, desde as afetuosas até mesmo as culturais. Assim, pretende-se aqui delinear um olhar um pouco diferente para Dancing Girls and Other Stories (1982), observando como, nas narrativas curtas desse livro, a atenção se volta para as questões da identidade cultural, principalmente em contextos multiétnicos. Na relação identitária cultural, há sempre um eu que produz um outro e desse envolvimento surgem vários conflitos: o conflito linguístico e, outros mais complexos como o comportamental, cultural e ideológico, os quais desencadeiam consequências muitas vezes negativas.

Os contos selecionados para esta análise são "The Man from Mars", o primeiro dos quatorze contos que compõem a coletânea, e "Dancing girls", que é homônimo ao título da obra completa. Esses contos foram escolhidos devido à sua temática estar visivelmente relacionada às questões da identidade no seu aspecto cultural, ou seja, por apresentarem um personagem estrangeiro tido como outro. O objetivo principal é refletir sobre como Atwood retrata nessas histórias esse outro, do ponto de vista de quem o vê e de quem o é. Dessa forma, os contos colocam em debate a alteridade a qual nos submetemos quando nos posicionamos no mundo, cultural e socialmente e, ainda, oferecem uma visão das relações culturais em contextos multiétnicos. Em algumas passagens dos demais contos, a temática sobre o estrangeirismo também ocorre, porém, não tão veemente como nas narrativas selecionadas para esta análise, justificando-se então o recorte do corpus deste trabalho.

"The Man From Mars” ou "O Homem de Marte” narra a história de Christine, que conhece um homem de estatura baixa e rosto não-familiar em um parque quando ele, em busca de uma informação, a interpela. Inicialmente, um encontro entre dois estranhos parece ser normal, até o momento em que o homem pede a Christine que lhe desenhe um mapa do prédio ao qual ele pretende chegar. O personagem ainda escreve seu nome em um papel e o entrega a jovem, pedindo-lhe que faça o mesmo para ele. Mesmo isso sendo algo incomum para dois desconhecidos, Christine 
acredita que isso deve pertencer à cultura do indivíduo e o faz, sem hesitar muito.

Logo em uma das primeiras impressões sobre o homem, o pensamento da personagem já o identifica como sendo um outro: "He was also what was referred to in their family as 'a person from another culture’: oriental without a doubt, though perhaps not Chinese. Christine judged he must be a foreign student and gave him her official welcoming smile" (ATWOOD, 1982, p.10). ${ }^{1}$ Quando Christine se despede, o homem persiste em manter contato com ela e lhe oferece ajuda, carregando a raquete de tênis que ela, para desenhar o mapa, havia deixado no chão. A partir de então, o estranho homem começa a acompanhá-la pelo caminho.

Para tentar prolongar o diálogo, o desconhecido pergunta a Christine se ela fala francês e, nessa mesma língua, ela responde que não. Ela tenta se despedir dele. Este insiste em acompanhar a protagonista até sua casa, oferta que, naturalmente por medo, ela rejeita. O homem é persistente e a segue, dizendo que ela é sua amiga, no intuito de estabelecer entre eles uma aproximação. A partir daí, começa a saga de Christine e o desconhecido homem estrangeiro, que a persegue incansável e inexplicavelmente, quebrando as 'regras' de comunicação que existem entre indivíduos desconhecidos. Nessa perseguição insistente, ele causará temor na jovem, mas também uma espécie de deleite, uma vez que ela se sente outra no seu próprio meio e quando vira objeto de ‘obsessão’ e atenção é como se sua existência adquirisse um valor maior.

“Dancing girls” retrata a história de Ann, uma jovem estudante de design urbano. Natural de Toronto, ela vive em uma pensão, um casarão com vários quartos, sem uma localização precisa. A protagonista convive com pessoas estrangeiras, com a proprietária da pensão, a Senhora Nolan e seus filhos, a qual se ocupa dos afazeres domésticos e maternos. Sempre sozinha em várias passagens do conto, a Senhora Nolan justifica a ausência de seu marido, que nunca aparecerá na diegese. As justificativas parecem uma espécie de conforto para a personagem. A pensão é o único ambiente a preocupar a Senhora Nolan, o que lhe possibilita continuamente observar com precisão a vida de seus clientes, julgando-os por seus hábitos e ações 'estrangeiras'. Na maior parte das vezes, ela os considera 'estranhos'.

O fluxo de hóspedes é contínuo, na medida em que alguns chegam e outros partem. Tudo ocorre normalmente na pensão, até que um novo hóspede, muito reservado, que quase não sai de seu quarto, intriga a Senhora Nolan. Esta, em uma de suas conversas com Ann, observa que esse hóspede muito quieto não faz nada além de pedir emprestado o aspirador de pó. Isso a perturba. Já em seu primeiro encontro com o vizinho, Ann sorri para ele, mas não é correspondida, o que a leva a concordar com sua anfitriã. Contudo, nada é tido de tão incomum em um homem que pouco sai de sua habitação e é visivelmente pouco sociável, até que um dia ele
${ }^{1}$ Ele também era o que na sua família era referido como 'uma pessoa de outra cultura': oriental, sem dúvida, embora talvez não chinês. Christine julgou que ele deveria ser um estudante estrangeiro e lhe deu seu sorriso oficial de boas-vindas. (tradução nossa) 
muda seus hábitos restritos. Surpreendentemente, do quarto do 'estranho' hóspede, ouve-se música alta e gargalhadas, levando a Senhora Nolan a querer reprimir esse comportamento ‘inadequado’ em sua propriedade.

Nitidamente preocupada e com toda sua autoridade, a dona da pensão vai até o quarto do hóspede, onde ela descobre que este participa de uma comemoração com alguns outros homens e três mulheres, as 'dancings girls'2, os quais dançavam e bebiam. Como já acreditava que por seus hábitos estranhos o homem poderia significar uma ameaça, a Senhora Nolan expulsa todos do quarto, ameaçando até mesmo chamar a polícia se eles não parassem com a balbúrdia. As 'dancing girls’ temem as autoridades; e assim, imediatamente, todos se retiram. Dessa forma, a Senhora Nolan continua mantendo a ordem na pensão e afirma suas ideias prévias sobre a 'esquisitice’ do hóspede. No final da história, Ann avista o homem, seus amigos e as 'dancing girls' em um parque, continuando a festa que a Senhora Nolan havia interrompido.

Conforme se observa nos resumos acima, nos dois contos o conceito de outro é colocado em pauta de forma bastante enfática. O próprio título, “The Man from Mars”, remete a uma série de possíveis sentidos. O homem de Marte pode significar alguém que é estrangeiro, muito diferente em termos culturais e com isso é simploriamente tido como alguém de 'outro planeta'. Ainda pode ser também considerado como um alienígena, um ser diferente de nós que normalmente repelimos por não sabermos nada de concreto sobre ele. Em inglês a palavra alien, alienígena, como substantivo é definida como: "1- someone who is not a citizen of the country they are living in; 2- A person or creature from a planet other than Earth.”3 $\mathrm{E}$ como adjetivo, uma de suas definições se refere a uma pessoa "completely different from what you usually do, feel, or know". (MACMILLAN PUBLISHERS LIMITED, 2007). O diferente assusta e já no título do conto, pode-se observar que Atwood prepara o leitor para mergulhar na temática sobre o outro.

No início da narrativa de "Dancing Girls”, há uma afirmação da presença de Ann como outra, quando a Senhora Nolan entra em seu quarto e pede à protagonista que vista seu 'native costume'5 para que as suas crianças a vejam. Ann sabe que realmente quem deseja vê-la não são as crianças e sim a própria Senhora Nolan, cujo prazer é deparar-se com o outro, com o diferente de si, o que também pode ser afirmado por ela ser a proprietária de uma pensão para estrangeiros. Assim que Ann fica sozinha com seus pensamentos, ela se pergunta: "What costume? Which land, this time?” (ATWOOD, 1982, p.196). ${ }^{6}$ Isto é, não é a primeira vez que ela é indagada para que se 'travista' como estrangeira, para que mostre a Senhora Nolan o seu 'verdadeiro eu', para que ela tenha regozijo sobre a dada condição da jovem.

\author{
${ }^{2}$ Dançarinas \\ (tradução nossa)
}

${ }^{3}$ 1-Alguém que não é um cidadão do país que está vivendo; 2- Uma pessoa ou criatura de outro planeta além a Terra. (tradução nossa).

${ }^{4}$ Completamente diferente do que geralmente você faz, sente ou sabe. (tradução nossa).

${ }^{5}$ Traje nativo. (tradução nossa).

\footnotetext{
${ }^{6}$ Que traje, qual terra, desta vez? (tradução nossa).
} 
Para que se possa discorrer sobre o outro visto nessas duas narrativas de Atwood, apresentamos a seguir os conceitos que norteiam esta análise. De acordo com Homi Bhabha (1998), estamos na era do além da fronteira, do prefixo pós, quando o tempo e o espaço se misturam e ressignificam as noções de tempo, de diferença e identidade. Isso faz com que tenhamos a impressão de que não estamos em um lugar exato, mas sim aqui e ali simultaneamente. Há uma sensação de estar sem direção, de estar 'para além de’ e, com isso, as singularidades das categorias de "raça” e "gênero" se dissiparam no entremeio das relações, o que, consequentemente, leva o sujeito a reivindicar suas posições, como a de raça, gênero, orientação sexual, entre outras, para encontrar sua identidade.

Para Bhabha (1998) é preciso encontrar na teoria os momentos que sinalizam as posições das singularidades das identidades. É preciso ir além das narrativas e subjetividades originais que fizeram com que as diferenças fossem estabelecidas, principalmente a cultural. A base para a subjetivação do sujeito são os chamados "entre-lugares", quando consegue os moldar passa-se a modelar também a própria sociedade. Deve-se, portanto, localizar os "estre-lugares” numa tentativa de quebrar com o presente para desconfigurar as narrativas dominantes que discriminam povos, grupos e sociedades e para que se possa desmantelar o vínculo, historicamente preestabelecido que articularam a diferença na história do mundo ocidental.

Com isso, o autor se dispõe a refletir sobre como um eu é levado a se identificar como outro, chamando isso de processo de identificação. Uma das condições desse processo refere-se à alteridade a que alguém se sujeita para poder se identificar quando o eu produz sua imagem num Outro e assume o papel que esse Outro reflete. Para Bhabha, “a identificação, como é pronunciada no desejo do Outro, é sempre uma questão de interpretação, pois ela é um encontro furtivo entre mim e um si-próprio, a elisão da pessoa e do lugar” (1998, p.87). Dessa forma, a imagem é sempre uma ilusão de presença, uma própria ausência, quando o sujeito se perde na tentativa de se encontrar. E, ainda, o outro é, ao mesmo tempo, o lugar de diferenciação e de origem de um eu. Para que nos posicionemos no mundo cultural, histórico e socialmente, captamos a imagem que recebemos do outro e passamos a reconhecê-la como a realidade, fato que é ilusório.

A identidade nunca é pré-definida e constituída: “- é sempre a produção de uma imagem de identidade e a transformação do sujeito ao assumir aquela imagem. A demanda da identificação - isto é, ser para um outro - implica na representação do sujeito na ordem diferenciadora da alteridade” (BHABHA, 1998, p.76-77). Há sempre uma tensão nesse processo de identificação, pois há o desejo também da troca de um com o outro, como, por exemplo, o desejo do escravo em ser o mestre, pois se um Outro se torna outro, tornando- se diferente dentre os diferentes, volta a ser um eu mesmo. Nesse sentido, Bhabha (1998) afirma que a identidade é o retorno de uma imagem de identidade e que com ela vem o rastro do Outro, de onde 
ela mesma emerge. Isto é, vivemos como um eu na sombra de um outro e vice-e-versa, pois não há um lugar ‘verdadeiro’ de identificação, como um espelho, onde a troca de imagens dá ao sujeito a ilusão de ser aquilo que vê.

O outro deve ser visto como a negação necessária de uma identidade primordial- cultural ou psíquica- que introduz o sistema de diferenciação que permite ao cultural ser significado como realidade linguística, simbólica, histórica. Se, como sugeri, o sujeito do desejo nunca é simplesmente um $E u$ Mesmo, então a Outro nunca e simplesmente um Aquilo Mesmo, um frente de identidade, verdade ou equívoco. (BHABHA, 1998, p. 86).

Paralelamente, também podemos recorrer ao pensamento de Jean Baudrillard, que também se dispôs a entender a duplicidade que nos divide e nos define. Em seu ensaio "Plastic Surgery for the other" (1994)" Baudrillard fala que entramos numa era de produzir o outro. Não há relação sentimental, tanto de amor ou ódio ao outro. Somente há um ato de produzir o outro. Para ele é como se o outro tivesse se tornado insuportável na sua alteridade radical (quando um corpo não considera o outro), devido a muitos fatores trazidos pela cultura massificante, neste caso com o aumento dos valores individuais na chamada, pós-modernidade. Quando se dá a falta da alteridade, não mais vista como destino, leva-se a produção do outro como diferença. Nas palavras do próprio autor: "in order to escape the world as destiny, the body as destiny, sex (and the other sex) as destiny, the production of the other as difference is invented" (BAUDRILLARD, 1994, s. p.). ${ }^{8}$

Não é por desejo ou diferenciação que um corpo se atrai pelo outro. É pelo que o autor chama de jogo de desejo. É por uma reciprocidade, por uma “alteridade”. O corpo não é mais visto como um lugar de relação dual e sim como um lugar de identificação, tornando-se então um "objeto ideal”. Para Baudrillard, o outro que persegue o sujeito é como se fosse uma morte, pois quando reconhecemos o duplo, tem-se a morte. Nesse cenário, não há mais uma identificação do corpo com o outro ou ainda, com o próprio corpo. Ele está fadado à inércia e à falta de representação. É a alteridade radical - a ausência pela presença.

Se o indivíduo já não se confronta com o outro, defronta-se consigo mesmo. Tornou-se seu anticorpo, por uma reviravolta ofensiva do processo imunitário, por um desajuste de seu próprio código, por uma destruição das próprias defesas. Ora, toda a nossa sociedade busca neutralizar a alteridade, destruir o outro como referência natural - na efusão asséptica da comunicação, na efusão interativa, na ilusão da troca e do contato. De tanta comunicação, a sociedade torna-se alérgica a si mesma. De tanta transparência a seu ser genético, biológico e cibernético, o corpo torna-se alérgico até sua sombra. Todo o espectro da alteridade negada ressuscita como processo autodestruidor. Isso é também a transparência do Mal. (BAUDRILLARD, 1990, p. 129).

\footnotetext{
7 “Cirurgia plástica para o outro” (tradução nossa). Título original: "Figures de L’alterite”. Versão em inglês traduzida por FrancoisDebrix. Disponível em: http:// www.egs.edu/faculty/ jean-baudrillard/ articles/plasticsurgery-for-theother/.
8 “A fim de escapar do mundo como destino, o corpo como destino, o sexo (e o sexo oposto) como destino, a produção do outro como diferença é inventada.” (1994, tradução nossa).
} 
O sujeito está condenado a si mesmo na sua própria repetição. E isso é uma espécie de desequilíbrio. Condenado a se relacionar com o outro de si mesmo ou seu próprio eu? Para Baudrillard (1990), a alteridade não é diferença e hoje vivemos um mundo da diferença, colocamos a própria linguagem num sistema de diferença, mas com isso acaba a relação entre ele e o sentido. Por isso não haveria sentido afirmar que a mulher seria o outro do homem, o louco o outro do normal, o selvagem do civilizado, pois não haveria fim em perguntar quem seria o outro do outro.

A diferença é utópica, não se separa e não se reconcilia o bem do mal e assim, o restante. Só se reconhece o outro nesse discurso da diferença. Os indígenas, por exemplo, pontua o autor, reconhecem seu direito de existência para que fiquem em reservas, para que continuem recebendo a posição de Outro e suas demandas. Não há a intenção de desmitificar o outro para se tornar um eu. Ainda para Baudrillard (1990): “o racismo não existe enquanto o outro é Outro, enquanto o Estrangeiro permanece estrangeiro. Começa a existir quando o outro se torna diferente, isto é, ameaçadoramente próximo. É aí que desperta a veleidade de mantê-lo à distância” (p. 136).

\section{O estranhamento pela presença do outro}

Em uma conversa com Ann, a Senhora Nolan assume sua felicidade em tê-la como uma hóspede, pois para ela Ann é mais do que uma estrangeira. Como normalmente dá atenção à proprietária, a jovem torna-se também uma quase amiga, ganhando intimidade e afeição. Na passagem seguinte, a proprietária da pensão expressa que Ann é diferente dos outros, deixando transparecer o estranhamento com relação a todos os estrangeiros que habitam sua pensão: “You're not, like, foreign. Not like most of them. It was his idea [her husbansd's], getting this big house to rent out. Not that he has to do the work or put up with them. You never know what they'll do" (ATWOOD, 1982, p.199). ${ }^{9}$

A passagem mostra o estranhamento quanto ao outro, uma espécie de repulsa e confronto, pois a fala da Senhora Nolan sugere a ideia de que “aguentá-los” e nunca saber “o que eles irão fazer” é difícil e também não é seguro. Quando se depara com o outro, o encontro é sempre um não-prazer; pois é quando a renúncia do próprio eu deve ser levada em conta para a aceitação do outro; o que normalmente acontece é a resistência em assegurar um eu - uma identidade - diferente e melhor do que a outra. Mesmo sendo ‘acolhida’ pela Senhora Nolan, Ann reflete que é realmente uma estrangeira, contrariando sua anfitriã:

Ann wanted to point out to her that she was indeed foreign, that she was just as foreign as any of the others, but she knew Mrs. Nolan would not understand. It would be like that fiasco in October. Wear your native costumes. She had responded to the invitation out of a sense of duty, as

\footnotetext{
${ }^{9}$ Você não é, tipo, estrangeira. Não como a maioria deles. Foi ideia dele [de seu marido], colocar esta grande casa para alugar. Não que ele tenha que fazer 0 trabalho ou suportálos. Você nunca sabe o que eles farão. (tradução nossa).
} 
well as one of irony. Wait till they get a load of my native costume, she'd thought, contemplating snowshoes and a parka but actually putting on her good blue wool suit. There was only one thing native costume reminded her of: the cover picture on the Missionary Sunday School paper they'd once handed out, which showed children from all the countries of the world dancing in a circle around a smiling white-faced Jesus in a bedsheet. That, and the poem in the Golden Windows Reader:

Little Indian, Sioux or Cree, Oh, don't you wish that you were me? (ATWOOD, 1982, p.199) $)^{10}$

Com base nas proposições de Bhabha (1998), observa-se na passagem acima a tensão que caracteriza a relação entre o eu e o outro. No poema citado pelo narrador extradiegético, o eu poético dirige-se aos indígenas de diversos grupos, perguntando-lhes sobre o desejo de serem igual a ele. A diferenciação se dá no encontro do ‘colonizado’ com o ‘colonizador' quando o segundo tem medo de que o primeiro tome o seu lugar ou, ao contrário, quando: "a fantasia do nativo é precisamente ocupar o lugar do senhor enquanto mantém seu lugar no rancor vingativo do escravo" (BHABHA, 1998, p.86). Aí se dá o problema da alteridade colonial, no $E u$ do colonialista e no Outro do colonizado, pois na busca incessante da diferenciação, a distância entre um e outro aumenta e, paradoxalmente, os dois se assemelham.

\section{O medo do outro}

Segundo Baudrillard (1990), devido à forma desesperada de direito à diferença, o homem pode mesmo chegar ao racismo, pois no momento em que o outro vira o outro, ele pode se tornar um monstro, uma aberração, a qual deve ser eliminada. O racismo ainda se dá no sistema linguístico, pois é desprovido de comprovantes científicos. O autor ainda conclui que não há um bom uso da lógica da diferença. Pois se não se aceita o outro, não se pode exterminá-lo. O outro se torna simplesmente “diferente” e não uma ameaça.

O outro é indestrutível na alteridade radical, mas ao mesmo tempo já está morto. Só sabemos o eu que representa o outro na sua própria diferença, daquilo que ele não sabe sobre ele mesmo. No desejo ao outro, buscamos o desejo de nós mesmos. Só produzimos o outro, quando o levamos a ficar estranho a si mesmo, quando o seduzimos. A xenofobia, por exemplo, é uma articulação discursiva que faz com que o outro realmente se sinta outro. Sendo Atwood canadense, ela está habituada a uma diversidade étnica e também aos confrontos que dessa sociedade nascem, quando ela mostra em suas obras um medo ao outro, ela denuncia o nacionalismo abatido, a xenofobia e o racismo como, nos termos de Hall (2005), são consequências transversais da globalização em sociedades híbridas.
${ }^{10}$ Ann queria mostrar que ela era de fato estrangeira, que ela era tão estrangeira quanto qualquer um dos outros, mas ela sabia que a senhora Nolan não entenderia. Seria como aquele fiasco em outubro.

Vista seus trajes nativos. Ela tinha respondido ao convite como um senso de dever, bem como uma ironia. Espere até que recebem uma carga de meu traje nativo, ela pensou, contemplando sapatos de neve e uma parca, mas, na verdade, vestindo seu bom terno de lã azul. Havia apenas uma coisa que traje nativo a fazia lembrar: a imagem de capa do jornal Escola Dominical Missionária que eles tinham entregado uma vez, o qual mostrava crianças de todos os países do mundo dançando em círculo em torno de um Jesus de cara branca sorrindo em um lençol. Isso, e o poema no Leitor das Janelas Douradas:

Pequeno índio, Sioux ou Cree,

Oh, você não deseja ser eu? (tradução nossa) 
Há varias tentativas de se tentar manter uma "purificação da identidade" e outros desmembramentos disso são o nacionalismo e fundamentalismo. O primeiro se refere às ideias de nacionalismo e tradição étnica e racial e o segundo, a ortodoxia religiosa. O nacionalismo então, tenta criar entidades políticas em torno de identidades culturais homogêneas, a fim de protegê-las e salvaguardá-las e o fundamentalismo, procura, baseado nas suas doutrinas religiosas, estabelecer um estado que não se oponha a elas. "A reafirmação de "raízes” culturais e o retorno à ortodoxia têm sido, desde há muito, uma das mais poderosas fontes de contra identificação em muitas sociedades e regiões pós-coloniais e do Terceiro Mundo (...)” (HALL, 2005, p.95).

Assim sendo, a passagem seguinte de "Dancing Girls” mostra a personagem Ann ponderando sobre o ato de repressão da Senhora Nolan contra o hóspede 'estranho'. Ann reflete sobre como o estereótipo faz a Arábia ser definida como diferentemente desconhecida - outra, observando a existência do medo e a visão homogeneizada que a sociedade da proprietária tem da cultura árabe: "Mrs. Nolan had called them that an euphemism, or perhaps because of an unconscious association with the word Arabian, the vaguely Arabian country"11 (ATWOOD, 1982, p.211). Dessa forma, Atwood denuncia a xenofobia e até mesmo, a falta de conhecimento sobre uma cultura outra. Além disso, uma das passagens de "The man from Mars” descreve o histórico estudantil da personagem Christine que é envolvida em um contexto multiétnico e ainda retrata implicitamente o medo que a sociedade da jovem possui em relação à cultura de um outro, novamente a árabe:

In high school she had been president of the United Nations Club; that year her school had been picked to represent the Egyptian delegation at the Mock Assembly. It had been an unpopular assignment - nobody wanted to be the Arabs - but she had seen it through. She had made rather a good speech about the Palestinian refugees (ATWOOD, 1982, p.10). ${ }^{12}$

Em “Dancing girls”, a Senhora Nolan dá à Ann uma descrição sobre um dos hóspedes que já havia passado pelo casarão. Ao fazê-lo, ela utiliza-se de noções estereotipadas e deixa transparecer um tipo de medo e preconceito em relação às tatuagens do sujeito e sua etnia, pelo fato dele ser pertencente - também - à cultura árabe. Depois de descrevê-lo fisicamente, ela afirma que ele era legal. E também pelo fato das tatuagens ou de seu turbante, a Senhora Nolan parece não entender o caráter híbrido das culturas em que turbantes ou tatuagens não significam necessariamente marcas de afiliação.

He's from one of them Arabian countries. Though I thought they wore turbans, or not turbans, those white things, like. He just has this funny hat,

\footnotetext{
${ }^{11}$ Senhora Nolan chamou eles daquilo, foi um eufemismo, ou talvez por causa de uma associação inconsciente com a palavra Árabe, o vago país Árabe. (tradução nossa)
}

\footnotetext{
${ }^{12}$ No colégio, ela tinha sido presidente do Clube das Nações Unidas; naquele ano sua escola foi escolhida para representar a delegação egípcia na Assembleia de Simulação. Foi uma tarefa impopular ninguém queria ser os árabes - mas ela a levou até o fim. Ela fez um bom discurso sobre os refugiados palestinos. (tradução nossa).
} 
sort of like the Shriners. He don't look much an Arab to me. He's got these tattoo marks on his face. But he's real nice (ATWOOD, 1982, p. 198-199). ${ }^{13}$

Para Bhabha (1998), o estereótipo atua estrategicamente no discurso, quando ele se constitui numa forma pré-dada de reconhecimento e identificação e repete aquilo que está ocupando esse lugar. A ambivalência do estereótipo é o que garante seu aparecimento repetitivo nas conjurações históricas e sociais. Deve-se fazer uma análise precisa dos processos de subjetivação do sujeito, para encontrar as dadas posições que estabeleceram os discursos dos estereótipos. O objeto deve ser também entendido em sua alteridade, como portador da articulação da diferença, que ilusoriamente origina a identidade, Bhabha (1998) afirma que o que deve ser questionado é o modo de representação da alteridade. Isto é, para o autor “(...) o estereotipo é um modo de representação complexo, ambivalente e contraditório, ansioso na mesma proporção em que é afirmativo, exigindo não apenas que ampliemos nossos objetivos críticos e políticos, mas que mudemos o próprio objeto de análise” (BHABHA, 1998, p. 110).

\section{Considerações Finais}

Reafirma-se a importância de Atwood como escritora canadense quando ela denuncia os conflitos culturais de sua sociedade através de seus personagens. Sendo mais que feminista, quando também retrata a feminilidade e seus conflitos, ela ainda faz parte da literatura canônica dos séculos XX e XI, e produz uma escrita nacionalista, afirmando que seus personagens falam por si mesmos, e não por ela. (MACPHERSON, 2010).

Pode-se observar que a relevância do conceito de outro em seus contos e que, ainda, a denúncia da xenofobia, do racismo e até mesmo da ignorância sobre uma outra cultura é elemento importante nessas narrativas. Em algumas passagens ela somente afirma a diferença, sem essa ser positiva ou negativa, como se pode observar na fala sobre a mãe de Christine, quando estava sendo interrogada pela polícia sobre o homem estranho: "Her mother volunteered that the thing about people from another culture was that you could never tell whether they were insane or not because their ways were so different” (ATWOOD, 1982, p.26) ${ }^{14}$. Isto é, um estranhamento pelo outro se dá naturalmente, é o princípio do reconhecimento de um eu/outro com um outro/eu - a alteridade. E no final do conto "The Dancing girls”, Atwood mostra a presença do 'outro' como outro e nada mais, através do pensamento de Ann que, durante um passeio, encontra o grupo expulso da pensão:

Groups of people were walking happily among the trees, holding hands, not just in two but in threes, fours, fives. The man from next door was there, in his native costume, and the mathematicians, they were all in their native
${ }^{13}$ Ele é de um dos países Árabes. Embora eu achasse que eles vestiam turbantes, turbantes não, tipo essas coisas brancas. Ele só tem este chapéu engraçado, como dos Shriners. Ele não parece muito árabe para mim. Ele tem essas marcas de tatuagem no rosto. Mas ele é muito legal. (tradução nossa).

${ }^{14}$ Sua mãe disse que a coisa sobre as pessoas de outra cultura era que você nunca poderia dizer se elas eram loucas ou não, porque suas maneiras eram tão diferentes. (tradução nossa) 
costume. Beside the stream a man was playing the flute; and around him, in long flowered robes and mauve scuffies, their auburn hair floating around their healthy pink faces, smiling their Dutch smiles, the dancing girls were sedately dancing. (ATWOOD, 1982, p. 212). ${ }^{15}$

A metáfora do estrangeiro como sendo o 'diferente' e a 'ameaça' ressoa fortemente e é, então, o principal tema encontrado nos dois contos, principalmente em relação à cultura árabe, que foi exposta em ambos os contos analisados. Pode-se inferir que se Atwood, no conto "The Man from Mars”, objetivasse somente retratar a perseguição sofrida por Christine, o homem estranho poderia ser simplesmente um personagem conterrâneo da jovem. Certamente se o tivesse feito, haveria outras significações. Mas ao mesmo tempo em que a escritora possibilita a reflexão sobre a condição feminina - a mulher como vítima - ela escolhe discorrer sobre um "homem de marte” e dessa forma, enfatiza a questão do estrangeiro, do outro. Atwood deixa implícitas as contradições que existem na demarcação de xenofobia ou racismo. Nas duas histórias não existem evidências e razões concretas para justificar a repressão e condenação dos personagens estrangeiros. O desencadeamento dos contos mostra esses personagens sendo reprimidos não por atos de ilegalidade, mas por suas ações consideradas 'estranhas' e 'ameaçadoras' e, logicamente, oriundas das suas posições de estrangeiros, de outros.

\section{Referências}

ATWOOD, M. Dancing Girls and Other Stories. New York: O. W. Toad, Ltd., 1982.

BHABHA, H K. O Local da Cultura. Tradução: Myriam Ávila, Eliana Lourenço de Lima Reis, Gláucia Renata Gonçalves. Belo Horizonte: Editora UFMG, 1998.

BAUDRILLARD, J. A Transparência do mal: Ensaio sobre os fenômenos extremos. Tradução: Estela dos Santos Abreu. Campinas: Papirus, 1990. 185 p.

. "Plastic surgery for the other.” From Baudrillard, Jean and Marc Guillaume, Figures de l’alterite. Paris: Descartes et Cie., 1994. Tradução: Francois Debrix. Disponível em: <http://www.egs.edu/faculty/jeanbaudrillard/articles/plastic-surgery-for-the-other/> Acesso em: 05 de nov. de 2012.

HALL, S. A identidade cultural na pós-modernidade. Tradução: Tomaz Tadeu da Silva, Guaira Lopes louro. 10. ed. Rio de Janeiro: DPeA, 2005. $102 \mathrm{p}$.
${ }^{15}$ Grupos de pessoas estavam caminhando alegremente entre as árvores, de mãos dadas, e não apenas em duas, mas em três, quatro, cinco. O homem da porta ao lado estava lá, em seu traje nativo, e os matemáticos, estavam todos com seus trajes nativos. Ao lado do córrego, um homem estava tocando flauta; e em torno dele, de longos roupões floridos e pantufas cor de malva, seus cabelos ruivos flutuando em torno de seus rostos rosados saudáveis, sorrindo seus sorrisos holandeses, as dançarinas estavam serenamente dançando. (tradução nossa) 
Macmillan English Dictionary for Advanced Learners, $2^{\text {nd }}$ edition. Oxford: Macmillan Publishers Limited: 2007.

MACPHERSON, H. S. The Cambrigde Introduction to Margaret Atwood. Cambrigde University Press: New york, 2010.

Enviado: 20/10/2014

Aprovado: 30/11/2014 